\title{
Dural Reduction Surgery: A Treatment Option for Frontotemporal Brain Sagging Syndrome
}

\author{
Emily Mostofi, Wouter I. Schievink, Valerie L. Sim
}

\begin{abstract}
Frontotemporal brain sagging syndrome is a dementia associated with hypersomnolence, personality changes, and features of intracranial hypotension on magnetic resonance imaging. The literature is sparse with respect to treatment options; many patients simply worsen. We present a case in which this syndrome responded to lumbar dural reduction surgery. Postoperative magnetic resonance imaging indicated normalization of brain sagging and lumbar intrathecal pressure. Although no evidence of cerebrospinal leak was found, extremely thin dura was noted intraoperatively, suggesting that a thin and incompetent dura could result in this low-pressure syndrome. Clinicians who encounter this syndrome should consider dural reduction surgery as a treatment strategy.
\end{abstract}

RÉSUMÉ: Chirurgie réductrice du sac dural : Une option thérapeutique dans le cas de l'affaissement de la région fronto-temporale du cerveau. Le syndrome d'affaissement (brain sagging) fronto-temporal constitue une démence associée à l'hyper-somnolence, à des changements de personnalité ainsi qu'à des traits d'hypotension intracrânienne mis en évidence par l'imagerie par résonnance magnétique (IRM). Peu d'écrits ont abordé les options de traitement. Qui plus est, nombreux sont les patients atteints dont la condition ira en se dégradant. Nous voulons présenter ici un cas à propos duquel ce type d'affaissement a bien répondu à une chirurgie réductrice du sac dural. Des examens postopératoires par IRM ont en effet indiqué une normalisation de l'affaissement fronto-temporal et de la pression lombaire intrathécale. Bien qu'aucune preuve de fuite de liquide cérébro-spinal n'ait été observée, une duremère extrêmement mince a été notée peropératoirement, ce qui suggère qu'une dure-mère amincie et inefficace pourrait résulter de ce syndrome d'hypotension. Les médecins cliniciens confrontés à un tel syndrome devraient du coup envisager la chirurgie réductrice du sac dural à titre de stratégie thérapeutique.

Keywords: Frontotemporal Dementia, Neuroimaging, Neurosurgery

doi:10.1017/cjn.2016.3

Can J Neurol Sci. 2016; 43: 593-595

\section{Case Report}

A 46-year-old right-handed man was referred for 2 years of progressive personality changes. He first developed hypersomnolence, mild frontal headaches not affected by postural change, and mild dysphagia for liquids. Eight months after onset, he developed memory loss and personality changes. He was charged with sexual assault, reckless driving, he started abusing cocaine, went on spending sprees, and developed hyperphagia.

Fourteen months after onset, a brain magnetic resonance imaging (MRI) scan revealed a sagging brain with herniation of the cerebral tonsils below the foramen magnum and flattening of the pons (Figure 1A). This was initially considered to be a Chiari I malformation and prompted referral to neurosurgery. Before surgical intervention, a psychiatric referral was made to address the unclear etiology of personality changes. After psychiatric assessment, the patient was referred to neurology with the suspicion of frontotemporal dementia. At this time, the patient's issues were hypersomnolence and apathy. He denied headache, depression, hallucinations, aphasia, prosopagnosia, or apraxia. He had occasional dysphagia with liquids, but no dysarthria, weakness, abnormal movements, or ataxia. He reported fingertip paresthesias. He had a suppressible urge to bend forward and squeeze his abdomen repeatedly. There were no significant autonomic signs or constitutional symptoms.

The patient was a welder, did not smoke or drink, and had no significant past medical, travel, or family history. He was on no medications and no longer used street drugs. Electrolytes, complete blood count, glucose, liver functions, $\mathrm{B}_{12}$, and thyroid-stimulating hormone were all normal. Closer evaluation of the original brain MRI revealed, in addition to the tonsillar herniation, the presence of subtle diffuse smooth thickening and enhancement of the supratentorial dura, raising the possibility of intracranial hypotension.

On examination, vitals were normal. He scored 27/30 on Montreal Cognitive Assessment, losing points for delayed recall. There were no frontal release signs. Cranial nerves were intact. Motor, reflexes, sensory, coordination, and gait examinations were normal. There were no extrapyramidal signs.

The combination of sagging brain on MRI, hypersomnolence, and frontotemporal dysfunction suggested a diagnosis of frontotemporal brain sagging syndrome. ${ }^{1}$ Although not fully understood, this syndrome is presumed to be secondary to intracranial hypotension. Based on this assumption, a lumbar blood patch was performed a full 19 months after symptom onset. The patient was pretreated with acetazolamide ${ }^{2}$ and given a $36-\mathrm{mL}$ epidural blood patch between lumbar vertebrae 2 and 3. Within 6 hours of the

From the Departments of Biological Sciences (EM); Medicine (VLS), University of Alberta, Edmonton, Alberta, Canada; Department of Neurosurgery, Cedars-Sinai Medical Center, Los Angeles, California (WIS)

Received SePtember 9, 2015. Final Revisions Submitted November 19, 2015 Date of Acceptance December 2, 2015.

Correspondence to: Valerie L. Sim, Centre for Prions and Protein Folding Diseases, 204 Brain \& Aging Research Building, University of Alberta, 8710-112 St, Edmonton, AB, Canada T6G 2M8. Email: valerie.sim@ualberta.ca 

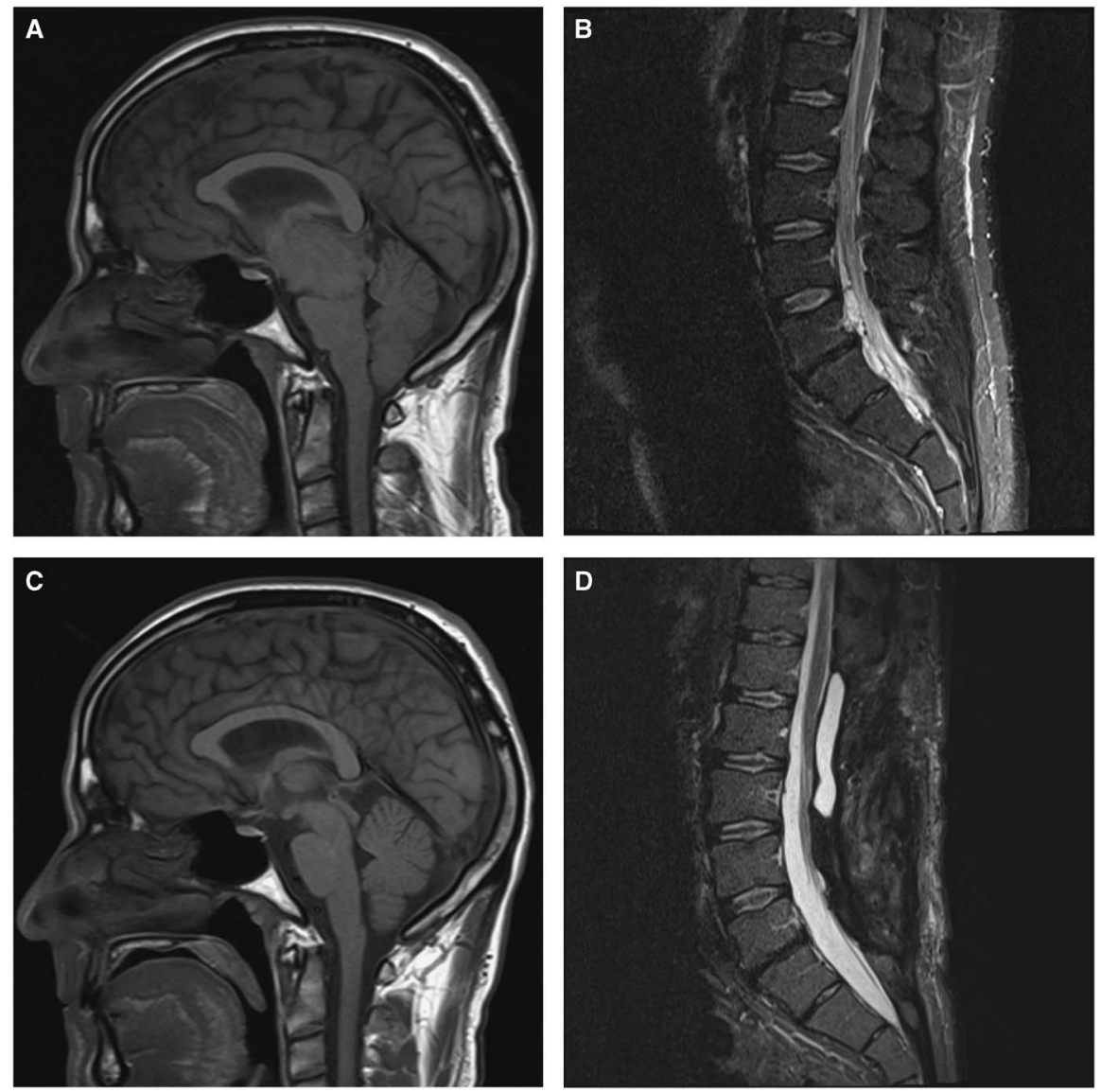

Figure 1: Pre- and postoperative MRI of brain and lumbar spine. (A, B): Sagittal MRI while symptomatic, before interventions. A) T1-weighted MRI of brain showing herniation of the cerebellar tonsils below the foramen magnum, distortion and flattening of the pons, and kinking of the medullary-spinal cord junction. B) Short T1 inversion recovery (STIR) MRI of lumbar spine showing enlarged ventral epidural venous plexus and small thecal sac. $(C, D)$ : Sagittal MRI while asymptomatic, postoperatively. C) T1-weighted MRI of brain showing normalization of brainstem anatomy and resolution of tonsillar herniation. D) STIR MRI of lumbar spine showing loss of ventral epidural venous plexus enlargement, increased thecal sac volume, and postoperative seroma.

procedure, symptoms had fully resolved; he was no longer somnolent, was behaving appropriately, and had no dysphagia.

Unfortunately, blood patching proved temporary, with symptoms returning within days to weeks despite repeat blood patching at the lumbar, thoracic, and cervical levels. Imaging studies (brain and spine MRI scan with contrast, nuclear medicine cisternography, computed tomography myelogram, digital subtraction angiography) failed to demonstrate a cerebrospinal fluid (CSF) leak or venous fistula. Only an enlarged ventral epidural venous plexus was seen at lumbar levels 3 to 5 , thought to reflect low intrathecal pressure and secondary engorgement (Figure 1B). An opening lumbar pressure was low at $10 \mathrm{~cm} \mathrm{H}_{2} \mathrm{O}$.

Two years after symptom onset, the patient underwent hemilaminectomies at lumbar vertebrae 3 and 4 followed by dural reduction surgery, a technique used to treat cases of refractory intracranial hypotension. ${ }^{3}$ Approximately 35 to $40 \mathrm{~mm}$ of extremely thin dura was removed and covered with a graft (Durepair). Postoperatively, the patient was immediately symptom-free, but after 5 weeks, symptoms returned. A repeat laminectomy from the first lumbar vertebral body to the level of the first sacral level was performed with further dural reduction. Again his symptoms fully resolved. Two days later, a pseudomeningocele developed, which was surgically repaired. He was then placed on $3000 \mathrm{mg}$ acetazolamide daily.

Significant complications developed after surgery, including sepsis with renal failure (requiring intubation and hemodialysis) and subsequent bilateral pulmonary emboli. All organ functions normalized within a week and he was discharged in stable condition.

Four months after surgery, an MRI scan showed normalization of the brain sagging, resolution of the enlargement of the lumbar ventral epidural venous plexus, and increased size of the thecal sac (Figure 1C, D), consistent with normalization of intrathecal pressures. Twelve months postsurgery, the patient remained symptom-free, his neurological examination was normal with a Montreal Cognitive Assessment score of 29/30, losing 1 point for recall (easily recalled with a category cue), and he had returned to work.

Fourteen months after his surgery, during the finalization of this manuscript, the patient began to develop a gradual return of his initial symptoms, including hypersomnolence and dysphagia. 
MRI scan showed a return of brain sagging and enlargement of the lumbar venous plexus. The dysphagia resolved with high-dose steroids ( $60 \mathrm{mg}$ prednisone daily) but within 2 weeks he started to develop behavioral changes despite steroid treatment. A 20-mL thoracic blood patch was administered, leading to immediate and complete resolution of all symptoms, allowing him to return to normal activities. Subsequent full spine MRI scan showed expected postoperative changes but no CSF leak. Cerebellar tonsil positioning had also improved.

\section{DISCUSSION}

Intracranial hypotension is usually attributed to a CSF leak, either spontaneous or iatrogenic, and causes postural headaches. However, symptoms of frontotemporal dementia can also occur. ${ }^{4,5}$ When a patient presents without postural headache, diagnosis and treatment may be delayed.

Symptoms of frontotemporal brain sagging syndrome, which can be considered an entity of spontaneous intracranial hypotension, include memory loss, hypersomnolence, and personality changes. ${ }^{1}$ Imaging shows brain sagging as seen in intracranial hypotension, but usually a CSF leak is not found and the pathogenesis is unclear. In this patient's case, the brain sagging was initially misinterpreted as a Chiari I malformation because the dural enhancement was quite subtle on imaging. A Chiari I malformation can also present with headache and neck pain, usually worsened with cough or Valsalva, and symptoms can also include dysarthria and dysphagia. On MRI scans, a Chiari I consists of herniation of the cerebellar tonsils through the foramen magnum, but flattening or kinking of the medulla is mild, if present at all, and there is no dural enhancement as seen in intracranial hypotension.

Extensive investigations in this patient did not demonstrate a CSF leak, but the dura was found to be incredibly thin during surgery, and we speculate that it may not have provided sufficient tensile strength to support an adequate intrathecal pressure. The sagging brain, enlarged lumbar venous plexus, low-normal opening pressure, and the resolution of these imaging findings postsurgery, support a low intrathecal pressure as the underlying cause. The responses to blood patching likely reflected transient changes in pressure from the injection volume rather than true patching of any leak. ${ }^{6,7}$

The reason for the clinical response to dural reduction surgery in this case probably also relates to changes in intrathecal pressure. The technique of dural reduction was developed to treat patients with recalcitrant spontaneous intracranial hypotension ${ }^{3}$ who have no CSF leak identifiable on spinal imaging. It consists of a lumbar laminectomy and the resection of a strip of dura followed by primary dural closure. The exact mechanism by which this surgical procedure is effective remains speculative but may involve the reduction of spinal CSF volume (i.e. less CSF is needed to maintain adequate CSF pressures) or a decrease of the compliance of the lower spinal CSF space by restoring the spinal dural sac and dural stiffness.

This case report highlights the importance of recognizing brain sagging syndrome and aggressively pursuing treatment. High-dose oral prednisone has been reported as effective for this condition in one case report, ${ }^{5}$ but our patient's response to steroids was minimal during his final relapse; he actually worsened on steroids. Here we demonstrate that dural reduction surgery is an alternate treatment option, although we cannot conclude it is curative. Because surgery is not without its risks, we suggest initial trials of blood patching to confirm a clinical response before proceeding with surgical intervention. A course of steroids may also be considered because it is more benign than surgery, but evidence is minimal for its effectiveness. In the future, if our patient develops recurrent relapses that require frequent blood patches, a final option is a wearable epidural infusion catheter system, which acts as an ongoing blood patch and has been used for intractable intracranial hypotension. ${ }^{8}$

\section{DisClosures}

The authors have nothing to disclose.

\section{REFERENCES}

1. Wicklund MR, Mokri B, Drubach DA, et al. Frontotemporal brain sagging syndrome: an SIH-like presentation mimicking FTD. Neurology. 2011;76:1377-82.

2. Ferrante E, Arpino I, Citterio A, et al. Epidural blood patch in Trendelenburg position pre-medicated with acetazolamide to treat spontaneous intracranial hypotension. Eur J Neurol. 2010;17: 715-9.

3. Schievink WI. A novel technique for treatment of intractable spontaneous intracranial hypotension: lumbar dural reduction surgery. Headache. 2009;49:1047-51.

4. Fishman RA, Dillon WP. Spontaneous intracranial hypotension causing reversible frontotemporal dementia. Neurology. 2002; 59:787.

5. Hong M, Shah GV, Adams KM, et al. Spontaneous intracranial hypotension causing reversible frontotemporal dementia. Neurology. 2002;58:1285-7.

6. Rouaud T, Lallement F, Choui R, et al. [Treatment of spontaneous intracranial hypotension by epidural saline infusion]. Rev Neurol. (Paris). 2009;165:201-5.

7. Pratt SD, Kaczka DW, Hess PE. Observational study of changes in epidural pressure and elastance during epidural blood patch in obstetric patients. Int J Obstet Anesth. 2014;23:144-50.

8. Schievink WI, Rosner HL, Louy C. A wearable epidural catheter infusion system for patients with intractable spontaneous intracranial hypotension. Reg Anesth Pain Med. 2015;40:49-51. 